\title{
Avaliação da política pública na gestão de recursos naturais renováveis: uma abordagem florestal
}

\section{Evaluation of public policies on renewable natural resources management: a forest approach}

\author{
Zung Che Yee $^{1^{*}}$; Ricardo Ralisch ${ }^{2}$
}

\section{Resumo}

\begin{abstract}
O trabalho teve como objetivo avaliar a eficiência do projeto de reflorestamento de palmito (Euterpe edulis Martius) na década de 70, no litoral paranaense, com recursos captados sob a égide da Lei n. 5.106/66 e Decreto-lei n. 1.134/70, numa abordagem florestal. A pesquisa foi realizada com base nos dados que foram fornecidos pelo Instituto Brasileiro do Meio Ambiente e dos Recursos Naturais Renováveis - IBAMA, autarquia que sucedeu as funções do extinto Instituto Brasileiro de Desenvolvimento Florestal - IBDF. Os resultados mostram ter havido um superdimensionamento da quantidade de plantas empregadas nos projetos, chegando a uma densidade de plantio de 5.000 árvores/ha, propiciando condições para o desvio dos recursos. Analisando o histórico dos planos de cortes da região, constata-se que, decorridos 32 anos dos incentivos, somente $1,22 \%$ das árvores implantadas foram cortadas através destes planos. A pesquisa confirma, portanto, a inexistência de correlação entre as áreas de plantio de palmito com os respectivos planos de corte, colocando sob suspeita os laudos de vistoria das implantações de reflorestamento elaborados pelo IBDF. O custo para unidade de árvore de palmito incentivado e cortado está na ordem de R $\$ 12,57$ (doze reais e cinqüenta e sete centavos), enquanto adquire-se atualmente a mesma árvore adulta por $\mathrm{R} \$ 2,00$ (dois reais) por unidade, caracterizando o mau uso de recursos públicos.
\end{abstract}

Palavras-chave: Eficiência de projetos de reflorestamento, recursos públicos

\begin{abstract}
The objective of this study was to evaluate the efficiency of palm tree (Euterpe edulis Martius) reforestation projects carried out in the 70s', in the coast of the State of Paraná, with funds collected under the Law 5,106/66 and the Judicial Decree 1,134/70, using a forest approach. Data were provided by IBAMA - The Brazilian Environment and Natural Resources Protection Agency, an autarchy that took on the function once exercised by the IBDF - Brazilian Institute for Forest Development. Results showed that there was an over-dimensioning of plant quantity in these projects, reaching a density level of 5,000 trees/ha, and creating conditions for resources embezzlement. Analysis of the cut down plans throughout history showed that, after 32 years of incentives, only $1.22 \%$ of planted trees had been chopped down, according to the plan. This research confirms the non-correlation between palm trees planting areas and cutting down plans, placing the inspection reports elaborated by the IBDF under suspicion. Cost per cut down and subsidized palm tree unit is $\mathrm{R} \$ 12.57$ (twelve reais and fifty seven cents), while, currently, this same adult tree can be bought for $\mathrm{R} \$ 2.00$ (two reais) each, characterizing mismanagement of public resources.
\end{abstract}

Key words: Reforestation projects efficiency, public funding

1 Eng $^{\mathbf{o}}$ Agrônomo, Doutorando em Agronomia na Universidade Estadual de Londrina UEL e Eng ${ }^{\circ}$ de Segurança do Trabalho pela UFPR. Curitiba-PR, zung@netpar.com.br

2 Eng ${ }^{\circ}$ Agrônomo, Doutor, Professor do Departamento de Agronomia da Universidade Estadual de Londrina - UEL, Caixa Postal 6.001, CEP 86051-990, Londrina, PR, ralisch@uel.br.

* Autor para correspondência. 


\section{Introdução}

Historicamente, as políticas públicas de gestão de recursos naturais renováveis têm sido divididas em dois enfoques distintos: comando e controle do desmatamento e incentivo ao reflorestamento.

Os incentivos ao reflorestamento no Estado do Paraná, destacam o denominado Programa de Incentivos Fiscais ao Florestamento e Reflorestamento - PIFPR, que consistiu no conjunto de atos normativos elaborados no período de 1965 a 1988, instituindo e regulamentando os incentivos florestais concedidos a essa atividade (LOPES et al., 2000).

São raras as literaturas que dizem respeito ao custo-benefício dessas políticas, exceto nas referências às fraudes e plantios malsucedidos, impedindo que os reflorestamentos se concretizassem (BACHA, 1995). Contudo, o estudo não especifica a natureza de tais fraudes e nem as razões dos insucessos, uma vez que os reflorestamentos devem sofrer as vistorias anuais e seqüenciais pelo órgão fiscalizador, o então Instituto Brasileiro de Desenvolvimento Florestal - IBDF, hoje assumido pelo Instituto Brasileiro do Meio Ambiente e dos Recursos Naturais Renováveis - IBAMA.

O presente artigo trata do estudo de caso sobre a eficiência do projeto de reflorestamento de palmito (Euterpe edulis Martius) na década de 70, no litoral paranaense, com recursos captados sob a égide da Lei n. 5.106 e Decreto-lei n. 1.134 dos quais ainda geram as autorizações de manejo sustentado. A identificação das possíveis irregularidades praticadas no passado, já prescritas, não consiste no objeto central do estudo, mas a compreensão dos mecanismos destas irregularidades, que podem contribuir na contenção de fraudes praticadas e, principalmente, para o aperfeiçoamento das políticas atualmente vigentes.

\section{Material e Métodos}

A pesquisa foi realizada em 2002 em Curitiba, PR abrangendo de três tipos de levantamentos distintos. O levantamento de dados sobre a somatória dos recursos destinados por diferentes rubricas de origens: Lei n. 5.106 e Decreto-lei n. 1.134 foram obtidos através de inventários florestais oficiais (BRASIL, 1984).

O levantamento dos dados de projetos de reflorestamento de palmito (Euterpe edulis Martius) no Estado do Paraná foi formalmente solicitado e autorizado pelo Instituto Brasileiro do Meio Ambiente e dos Recursos Naturais Renováveis - IBAMA, que sucedeu as funções do extinto Instituto Brasileiro de Desenvolvimento Florestal - IBDF, autarquia a que concedeu as autorizações originárias. Foram compilados e tabulados os dados sobre: áreas, número de árvores incentivadas, vistorias realizadas pela autarquia fiscalizadora, municípios de abrangência e recursos envolvidos por categoria de recursos.

Os recursos monetários envolvidos foram convertidos em dólar americano, data-base de dezembro do respectivo ano sob análise, obtido através de informes oficiais do Banco Central do Brasil, Delegacia Regional do Paraná. Foram realizados os levantamentos de planos de cortes concedidos dos projetos incentivados de reflorestamento de palmito (Euterpe edulis Martius) comparando com a quantidade das árvores efetivamente plantadas, com o propósito de identificar a somatória dos quantitativos das árvores autorizadas para o corte, dentro do espaço temporal de 32 anos.

Os projetos de reflorestamento de palmito (Euterpe edulis Martius) autorizados pelo extinto Instituto Brasileiro de Desenvolvimento Florestal IBDF, sob a égide do Decreto n. 5.106 e pelo Decreto-lei n. 1.134, ocorreram na década de 70, mais especificamente entre os anos de 1970 a 1977. Segundo os dados contidos na Tabela 1, demonstrase que foi autorizada, no mesmo período, a concessão de reflorestamentos de palmiteiros no total de 138.551,18ha, dos quais 71,9\% através da Lei n. 5.106 e $28,1 \%$ através do Decreto-lei n. 1.134.

Quanto ao número de árvores plantadas, foram comprovados através de vistorias contidas nos 
respectivos projetos, tidos como realizados. $\mathrm{Na}$ totalidade das áreas reflorestadas segundo os dados contidos na Tabela 1 somam o total de 728.676.237 árvores, sendo 523.962.387 sob a égide da Lei n. 5.106 e 204.713.850 através do Decreto-lei n. 1.134.

Analisando os projetos individualizados, verificouse que, no início dos projetos de reflorestamentos, os quantitativos de árvores plantadas por hectare eram variados, podendo ser flexibilizados no patamar de 5.000 árvores/ha até 10.000 árvores/ha. Posteriormente, foram unificados com a capacidade de lotação máxima de 5.000 árvores/ha.

Tabela 1. Áreas e número de árvores reflorestadas de palmito (Euterpe edulis Martius) no Estado do Paraná - Lei n. 5.106 e Decreto-lei n. 1.134.

\begin{tabular}{|c|c|c|c|c|c|c|}
\hline & \multicolumn{2}{|c|}{ Lei n. 5.106} & \multicolumn{2}{|c|}{ Decreto-lei n. 1.134} & \multicolumn{2}{|c|}{ Total } \\
\hline Ano & $\begin{array}{l}\text { Área } \\
\text { (ha) }\end{array}$ & $\begin{array}{c}\mathrm{N}^{0} \text { de } \\
\text { árvores }\end{array}$ & $\begin{array}{l}\text { Área } \\
\text { (ha) }\end{array}$ & $\begin{array}{c}\mathrm{N}^{0} \mathrm{de} \\
\text { árvores }\end{array}$ & $\begin{array}{l}\text { Área } \\
\text { (ha) }\end{array}$ & $\begin{array}{c}\mathrm{N}^{\mathbf{0}} \text { de } \\
\text { árvores }\end{array}$ \\
\hline 1970 & $1.321,60$ & 8.878 .000 & - & - & $1.321,60$ & 8.878 .000 \\
\hline 1971 & 672,00 & 3.954 .000 & $1.510,00$ & 1.190 .000 & $2.182,00$ & 5.144 .000 \\
\hline 1972 & $6.406,39$ & 33.495 .617 & $2.020,00$ & 11.200 .000 & $8.426,39$ & 44.695 .617 \\
\hline 1973 & $17.106,41$ & 87.078 .745 & $1.040,00$ & 7.900 .000 & $18.146,41$ & 94.978 .745 \\
\hline 1974 & $14.357,29$ & 71.786 .925 & $7.247,34$ & 48.319 .200 & $21.604,63$ & 120.106 .125 \\
\hline 1975 & $34.694,55$ & 173.475 .750 & $9.543,00$ & 48.390 .000 & $44.237,55$ & 221.865 .750 \\
\hline 1976 & $24.766,67$ & 143.678 .350 & $8.798,43$ & 43.992 .150 & $33.565,10$ & 187.670 .500 \\
\hline 1977 & 323,00 & 1.615 .000 & $8.744,50$ & 43.722 .500 & $9.067,50$ & 45.337 .500 \\
\hline 1978 & - & - & - & - & - & - \\
\hline 1979 & - & - & - & - & - & - \\
\hline Total & $99.647,91$ & 523.962 .387 & $38.903,27$ & 204.713 .850 & $138.551,18$ & 728.676 .237 \\
\hline
\end{tabular}

Inventário Nacional das Florestas Plantadas nos Estados do Paraná e Santa Catarina. Brasília, IBDF, Fonte: Machado (1984).

\section{Resultados e Discussão}

\section{Análise dos projetos de reflorestamento de palmito (Euterpe edulis Martius) concedidos pelo extinto IBDF}

Sobre a distribuição de projetos, conforme a Tabela 2, constata-se que, em termos numéricos, dos 266 projetos concedidos, 118 projetos foram implantados no município de Guaraqueçaba; 57 projetos no município de Guaratuba; 35 projetos no Município de Antonina; 17 projetos em Campina Grande do Sul e 13 projetos em Morretes. Em termos percentuais de participação, representam, respectivamente: $44,4 \%, 21,4 \%, 13,2 \%, 6,4 \%$ e $4,9 \%$. Registra-se que nos municípios de Guaraqueçaba e Antonina, que integram a Comarca de Antonina, somam $57,5 \%$ da totalidade das árvores reflorestadas. 
Yee, Z. C.; Ralisch, R.

Tabela 2. Distribuição de número de projetos de reflorestamento de palmito (Euterpe edulis Martius) no Estado do Paraná, por Município - Lei n. 5.106 e Decreto-lei n. 1.134.

\begin{tabular}{ccccccccccccccc}
\hline & & & 1 & \multicolumn{11}{c}{ M u n i c p i o s } \\
\hline $\begin{array}{c}\mathrm{N}^{\circ} \text { de } \\
\text { projetos }\end{array}$ & 118 & 57 & 35 & 17 & 13 & 12 & 5 & 3 & 2 & 1 & 1 & 1 & 1 & 266 \\
$\begin{array}{c}\% \\
\text { em área }\end{array}$ & 44,4 & 21,4 & 13,2 & 6,4 & 4,9 & 4,5 & 1,9 & 1,1 & 0,8 & 0,4 & 0,4 & 0,4 & 0,4 & 100 \\
\hline
\end{tabular}

Municípios: 1 - Guaraqueçaba; 2 - Guaratuba; 3 - Antonina; 4 - Campina Grande do Sul; 5 - Morretes; 6 - Paranaguá; 7 - São José dos Pinhais; 8 - Ibaiti; 9 - Adrianópolis; 10 - Matinhos; 11 - Terra Boa; 12 - Joaquim Távora; 13 Bocaiúva do Sul.

$\mathrm{Na}$ análise desagregada de projetos por diferentes legislações, verifica-se que de acordo com os reflorestamentos sob o amparo da Lei n. 5.106, o município de Guaraqueçaba foi contemplado com $46,5 \%$ dos projetos autorizados, seguido dos municípios de Guaratuba (19,7\%), Antonina (12,0\%), Campina Grande do Sul (6,0\%) e Morretes (5,5\%). Quanto aos projetos contemplados sob a égide do Decreto-lei n. 1.134, constata-se que se encontram concentrados nos municípios: Guaraqueçaba $(39,8 \%)$, Guaratuba (25,3\%), Antonina (15,7\%), Campina Grande do Sul (7,2\%) e Morretes (6,0\%).
A somatória dos custos de todos os projetos implantados, nas duas legislações, representa, segundo os dados contidos na Tabela 3 ao montante de US\$ 47.778.250,73 (quarenta e sete milhões, setecentos e setenta e oitenta mil e duzentos e cinqüenta dólares americanas e setenta e três centavos), que a cotação de agosto/2005, a R \$ 2,34 (dois reais e trinta e quatro centavos), equivale a $\mathrm{R} \$$ 111.801.106,70 (cento e onze milhões, oitocentos e um mil e cento e seis reais e setenta centavos).

Tabela 3. Custos de implantação de projetos de reflorestamento de palmito (Euterpe edulis Martius).

\begin{tabular}{cccc}
\hline & Decreto n. 5.106 & Decreto-lei n. 1.134 & \multicolumn{1}{c}{ Total } \\
\hline US\$ & $34.001 .090,65$ & $13.777 .160,08$ & $47.778 .250,73$ \\
R\$ * & $79.562 .552,12$ & $32.238 .554,58$ & $111.801 .106,70$
\end{tabular}

* Valores de agosto de 2005.

Análise dos projetos de reflorestamento de palmito (Euterpe edulis Martius) concedidos pelo extinto IBDF, com os respectivos planos de cortes até hoje concedidos pelo IBDF/ IBAMA.

Analisando-se os laudos de vistorias das áreas reflorestadas do extinto Instituto Brasileiro de Desenvolvimento Florestal - IBDF, constata-se ter havido uma implantação de 728.676.237 árvores de palmito na região.
Já a verificação dos planos de corte, que consistem nas autorizações de cortes dos palmiteiros reflorestados concedidos até agosto/2002 e realizados junto ao IBAMA constatou, conforme os dados contidos na Tabela 4, que as autorizações de corte correspondem tão somente a 8.895.981 árvores, equivalente a $1,22 \%$ da quantidade supostamente reflorestada, decorrida 32 anos após as primeiras implantações, para uma cultura com ciclo médio de 10 anos (NOGUEIRA, 1977). 
Tabela 4. Número de árvores reflorestadas e planos de cortes concedidos de reflorestamento de palmito (Euterpe edulis Martius) no Estado do Paraná - Lei n. 5.106 e Decreto-lei n. 1.134.

\begin{tabular}{cccc}
\hline & $\begin{array}{c}\mathbf{N}^{\mathbf{}} \text { árvores reflorestadas } \\
\text { confirmadas pelas vistorias (A) }\end{array}$ & $\begin{array}{c}\mathbf{N}^{\mathbf{0}} \text { de árvores autorizadas } \\
\text { Plano de corte (B) }\end{array}$ & $\begin{array}{c}\text { (B) / (A) } \\
\mathbf{x ~ 1 0 0}\end{array}$ \\
\hline Total & 728.676 .237 & 8.895 .981 & 1,22 \\
Lei n. 5.106 & 523.962 .387 & 7.601 .270 & 1,45 \\
Decreto-lei n. 1.134 & 204.713 .850 & 1.294 .711 & 0,63 \\
\hline
\end{tabular}

Analisando de acordo com as diferentes legislações, verifica-se que, sob a égide da Lei n. 5.106 e que tiveram nas suas vistorias a confirmação da real implantação, o reflorestamento de 523.962.387 árvores, sendo autorizadas para o corte, 7.601.270 árvores, ou seja, $1,45 \%$ da totalidade de árvores implantadas, após 32 anos das primeiras implantações. A análise de tais dados coletados permitiu verificar a seguinte representatividade entre os municípios: Guaraqueçaba $(68,1 \%)$, Guaratuba (21,5\%), Antonina (7,2\%), Paranaguá $(3,0 \%)$ e São José dos Pinhais $(0,2 \%)$.

Ao ser comparado com os dados de Projetos Implantados no Estado do Paraná por Municípios, objeto da Tabela 3, verifica-se que não existe relação direta entre os Municípios que mais possuem projetos implantados com os que possuem mais planos de corte.

Considerando que os cinco municípios contendo maiores números de árvores implantadas foram, na ordem decrescente: Guaraqueçaba (275.068.212 árvores), Guaratuba (65.496.325 árvores), Antonina (61.626.550 árvores), Campina Grande do Sul (39.496.350 árvores) e Morretes (29.245.450 árvores), confirmam que não existe relação direta com o corte de palmito com a respectiva implantação. Posto que, os municípios de Campina Grande do Sul e Morretes, respectivamente $4^{\circ}$ e $5^{\circ}$ lugares em número de árvores implantadas, sequer houve a caracterização de respectivos planos de cortes de palmitos.

A análise sob a ótica restrita do Decreto-lei n. 1.134, verifica-se que, entre as árvores reflorestadas que tiveram nas suas vistorias a confirmação da real implantação, de 204.713.850 árvores, foram autorizadas para o corte de 1.294.711 árvores, ou seja, $0,6 \%$ da totalidade de árvores implantadas, depois de decorridos 32 anos após as primeiras implantações. Neste caso, a representatividade entre os municípios foi: Guaratuba (52,8\%), Guaraqueçaba $(18,1 \%)$, Antonina (15,2\%), Matinhos (9,5\%) e Paranaguá $(4,5 \%)$.

Ao ser comparado com os dados de projetos implantados no Estado do Paraná por Municípios, objeto da Tabela 2, verifica-se que, de forma análoga a Lei n. 5.106, não existe relação direta entre os municípios que mais possuem projetos implantados com os que possuem mais planos de corte.

Considerando que os cinco municípios contendo os maiores números de árvores implantadas foram, na ordem decrescente: Guaratuba (77.361.700 árvores), Guaraqueçaba (67.677.500 árvores), Antonina (24.157.150 árvores), Campina Grande do Sul (9.275.000 árvores) e Matinhos (7.450.000 árvores), confirmam que não existe relação direta com o corte de palmito com a respectiva implantação. Posto que, o município de Campina Grande do Sul, que corresponde o $4^{\circ}$ lugar em número de árvores implantadas, sequer houve a caracterização de planos de corte de palmitos.

\section{Conclusões}

Os recursos para os reflorestamentos avaliados foram mal aplicados, visto que os custos da unidade incentivada e cortada ficaram na ordem de $\mathrm{R} \$ 12,57$ por planta.

As vistorias de implantação de reflorestamentos realizados pelo IBDF nos casos analisados foram ineficientes. 
A ineficiência das vistorias de implantação coloca em dúvida a efetiva implantação dos reflorestamentos.

Não houve um estudo criterioso por parte do IBDF, do ponto de vista florestal, sobre a adequação da densidade de reflorestamento, propiciando condições de financiamento de 5.000 árvores de palmito (Euterpe edulis Martius) por hectare o que propiciou condições para a má utilização de recursos públicos.

\section{Agradecimentos}

Ao Instituto Brasileiro do Meio Ambiente e dos Recursos Naturais Renováveis - IBAMA, Superintendência do Paraná, pela concessão parcial dos dados da pesquisa.

\section{Referências}

BACHA, C. J. C. A. Análise custo-benefício dos programas federais de incentivos ao reflorestamento no Brasil. In: CONGRESSO BRASILEIRO DE ECONOMIA E SOCIOLOGIA RURAL, 33., 1995, Curitiba. Anais... Curitiba, 1995, p.1.007-1.030.

BRASIL, Instituto Brasileiro de Desenvolvimento Florestal, Departamento de Economia Florestal, Inventário florestal nacional reflorestamento Paraná e Santa Catarina. Brasília: IBDF, 1984.

LOPES, I. V.; BASTOS FILHO, G. S.; BILLER, D.; BALE, M. (org.) Gestão ambiental no Brasil: experiências e sucessos. 3. ed. Rio de Janeiro: FGV, 2000.

MACHADO, S. A. (Coord.) Inventário nacional das florestas plantadas nos estados do Paraná e Santa Catarina. Brasília: Instituto Brasileiro de Desenvolvimento Florestal, 1984.

NOGUEIRA, J. N. Palmito - produção, préprocessamento e transformação agroindustrial. São Paulo: Secretaria da Indústria e Comércio, Ciência e Tecnologia do Governo do Estado de São Paulo, 1977, p.66, (Série Extensão Agroindustrial, v.6). 